

\title{
High iodine dietary intake is associated with type 2 diabetes among women of the E3N-EPIC cohort study
}

Francesca Romana Mancini, Kalina Rajaobelina, Courtney Dow, Tina

Habbal, Aurélie Affret, Beverley Balkau, Fabrice Bonnet, Marie-Christine

Boutron-Ruault, Guy Fagherazzi

\section{To cite this version:}

Francesca Romana Mancini, Kalina Rajaobelina, Courtney Dow, Tina Habbal, Aurélie Affret, et al.. High iodine dietary intake is associated with type 2 diabetes among women of the E3N-EPIC cohort study. Clinical Nutrition, inPress, 10.1016/j.clnu.2018.08.015 . hal-01928226

HAL Id: hal-01928226

https://hal-univ-rennes1.archives-ouvertes.fr/hal-01928226

Submitted on 24 Nov 2018

HAL is a multi-disciplinary open access archive for the deposit and dissemination of scientific research documents, whether they are published or not. The documents may come from teaching and research institutions in France or abroad, or from public or private research centers.
L'archive ouverte pluridisciplinaire HAL, est destinée au dépôt et à la diffusion de documents scientifiques de niveau recherche, publiés ou non, émanant des établissements d'enseignement et de recherche français ou étrangers, des laboratoires publics ou privés. 
1 High iodine dietary intake is associated with type 2 diabetes among

2 women of the E3N-EPIC cohort study.

3 Francesca Romana Mancini, ${ }^{1,2}$ Kalina Rajaobelina, ${ }^{1,2}$ Courtney Dow, ${ }^{1,2}$ Tina Habbal, ${ }^{1,2}$ Aurélie

4 Affret, ${ }^{1,2}$ Beverley Balkau, ${ }^{1,3}$ Fabrice Bonnet, ${ }^{1,4}$ Marie-Christine Boutron-Ruault, ${ }^{1,2}$ Guy

5 Fagherazzi ${ }^{1,2}$

6 1: CESP, INSERM U1018, Univ. Paris-Sud, UVSQ, Université Paris-Saclay, Villejuif Cedex, F-

794805 , France

8 2: Gustave Roussy, Villejuif, F-94805, France

9 3: University Versailles, Saint Quentin, University Paris-Sud, Villejuif, France

10 4: CHU Rennes, Université de Rennes 1, France

11 Corresponding author: Guy Fagherazzi, $\mathrm{PhD}$

12 Inserm U1018, Centre for Research in Epidemiology and Population Health (CESP)

13 "Health across Generations" Team, Gustave Roussy, Espace Maurice Tubiana

14114 rue Edouard Vaillant, 94805 Villejuif Cedex, France

15 Email: guy.FAGHERAZZI@gustaveroussy.fr

16 FR Mancini, K Rajaobelina,' C Dow, T Habbal, A Affret, B Balkau, F Bonnet, MC Boutron-

17 Ruault, and G Fagherazzi have no conflict of interest to declare. 
Background: Iodine is an essential micronutrient needed for the production of thyroid hormones.

Consequently, iodine insufficient and excessive intakes are associated with thyroid disorders.

Despite the increase in diabetes prevalence worldwide and the close relationship between thyroid function and the risk of diabetes, the relationship between iodine intake and diabetes has been overlooked. The objective of the present study is to investigate the link between iodine intake and the risk of type 2 diabetes.

Methods: Cox proportional hazards regression models adjusted on potential confounders were used to calculate the hazard ratios and $95 \%$ confidence intervals for the associations between dietary iodine intake and type 2 diabetes risk among 71264 women of the E3N-EPIC cohort. Results: The average iodine intake in the study population was $155.6 \mu \mathrm{g} /$ day $( \pm 47.1 \mu \mathrm{g} /$ day $)$. After adjusting for the main risk factors for diabetes, for hypo/hyperthyroidism, as well as for phosphorus intakes and consumption of dairy products and seafood, the hazard ratios $(95 \% \mathrm{CI})$ for type 2 diabetes of women in the $4^{\text {th }}(160.7-190.5 \mu \mathrm{g} /$ day $)$ and $5^{\text {th }}(190.6-596.8 \mu \mathrm{g} /$ day $)$ quintiles groups of iodine intake were $1.27(1.10-1.47)$ and 1.28 (1.07-1.53), respectively, compared to women with iodine intake below the $1^{\text {st }}$ quintile $(29.3-116.9 \mu \mathrm{g} /$ day).

Conclusion: This is the first study to investigate the relationship between dietary iodine intake and the risk of developing type 2 diabetes. More studies are warranted to further investigate the health effects of chronic high iodine intake, and in particular to investigate the biological mechanisms that underlie the association between iodine intake and type 2 diabetes. Key words: Iodine, type 2 diabetes, cohort study, E3N-Epic 
41

42

43

44

45

46

47

48

49

\section{Introduction}

Iodine is an essential micronutrient needed for the production of thyroid hormones. Iodine is almost completely absorbed by the small intestine and the kidney is the main route of excretion $(1,2)$.

The World Health Organization (WHO)/ Food and Agriculture Organization of the United Nations (FAO) recommend a daily iodine intake of $150 \mu \mathrm{g} /$ day (equal to $2.0 \mu \mathrm{g} / \mathrm{kg}$ body weight per 7 days) in adults (3). This value was also confirmed by the European Food Safety Authority (EFSA) (4). The main sources of iodine in the diet are seafood (such as fish, crustaceans, mussels, algae), eggs, dairy products, and iodine-enriched salt (4).

Iodine deficiency is associated with a higher frequency of goiter and hypothyroidism. Conversely, high intakes of iodine can accelerate the development of thyroid disorders such as hypothyroidism or hyperthyroidism, increase the incidence of autoimmune thyroiditis and increase the risk of thyroid cancer $(5,6)$.

There is a close relationship between type 2 diabetes and thyroid dysfunction (7). Studies have shown that thyroid dysfunction is more common in the diabetic population than in the nondiabetic population and that altered thyroid function may affect glucose tolerance and worsen metabolic control in people with diabetes $(8,9)$. Hypothyroidism is characterized by insulin resistance and is associated with a reduced production of hepatic glucose (10-13). On the other side, hyperthyroidism has been associated with increased insulin resistance and greatly aggravates metabolic control in people with diabetes, promoting diabetic ketoacidosis (14-16).

Despite the increase in diabetes prevalence worldwide (17) and the close relationship between thyroid function and the risk of diabetes, the association between iodine intake and diabetes has been overlooked. 
In this context, we decided to study the link between iodine intake and the risk of type 2 diabetes in the large E3N-EPIC cohort.

\section{Material and methods}

The E3N-EPIC cohort

E3N-EPIC is a French cohort study of 98,995 women born between 1925 and 1950 and it was initiated in 1990 (18). It is the French component of the European Prospective Investigation into Cancer and Nutrition (EPIC) (19), and the EPIC-InterAct sub-study (interaction of genetic and lifestyle factors on the incidence of type 2 diabetes) (20). The data are available from postal questionnaires that participants returned every 2-3 years, in addition to a database of drug reimbursement that exists since 2004 from the medical records of the participants (Mutuelle Générale of National Education). The average response rate for each of the eleven questionnaire cycles was $83 \%$ and $<3 \%$ of the women never responded to a follow-up questionnaire. All women signed letters of informed consent, according to the French National Commission for Computer Data and Individual Liberty (CNIL).

\section{Study population}

Of the 74,522 women who responded to the diet-history questionnaire sent in 1993, we excluded those who did not complete any questionnaire after the diet history questionnaire $(n=935)$, those with an aberrant energy intake (1\% and $99 \%$ extremes of the energy intake/energy expenditure ratio, $n=1467)$, and the cases of diabetes detected before the food history questionnaire $(n=$ 856). Thus, our study population included 71,264 women, of whom $2,665(3,7 \%)$ had developed type 2 diabetes during follow-up (June 1993-Febuary 2012). 
Before 2004, all potential cases were identified with the follow-up questionnaires through self-reporting of diabetes, diabetes diet, diabetes drugs, and hospitalization for diabetes. All potential cases were then contacted and asked to answer a diabetes-specific questionnaire that included questions on the circumstances of diagnosis (year of diagnosis, symptoms, biological exams, fasting, or random glucose concentrations at diagnosis), diabetes therapy (prescription of diet or physical activity, list of glucose lowering drugs taken), last measures of fasting glucose and $\mathrm{Hb} 1 \mathrm{Ac}$ levels.

Potential diabetes cases were finally validated if they declared at least one of these criteria:

(1) fasting plasma glucose $\geq 7 \cdot 0 \mathrm{mmol} / \mathrm{l}$; random glucose $\geq 11 \cdot 1 \mathrm{mmol} / 1$ at diagnosis;

(2) self-report of glucose lowering medication use;

(3) last values of fasting glucose or HbA1c concentrations $\geq 7 \cdot 0 \mathrm{mmol} / \mathrm{l}$ or $\geq 7 \%$;

After 2004, all potential cases were identified through the drug reimbursement insurance database: women reimbursed at least twice for glucose lowering medications within one year period were classified as validated cases of diabetes.

Within the E3N cohort to date diabetes cases have been validated up to the year 2012.

\section{Evaluation of iodine intake}

Usual diet over the previous year was assessed by a validated 208-items diet-history questionnaire in 1993, structured according to the French meal pattern. Questions were asked about all times of the day when food or drinks were consumed, from breakfast to after-dinner snacks, thus including all food or drink intakes between meals, such as appetizers before lunch or dinner. The validity and reproducibility of the questionnaire have been previously described (21). Foods were converted to macro- and micronutrients using a food composition table derived from the official French food composition table (CIQUAL) (22), and supplemented 
where necessary by the McCance and Widdowson tables (23). Daily dietary iodine intakes were then estimated for each woman in the study.

\section{Statistical analysis}

The contribution of different food groups to the total iodine intake was calculated.

Due to the strong correlation between energy and micronutrient intake, iodine intake, as well as intakes of all micronutrients, was energy adjusted using the residual method $(24,25)$. Cox multivariable regression models, with age as the time scale, were used to estimate hazard ratios (HR) and 95\% confidence intervals $(95 \% \mathrm{CI})$ for T2D associated with dietary iodine intake. Follow-up started at the age the dietary questionnaire was completed, and ended at the age of the first of the following events: diagnosis of diabetes, death, or loss to follow-up.

Women were classified into quintile groups according to energy adjusted iodine intake, and the lowest quintile was used as the reference category in the models.

We first performed a univariate analysis (model 0 ), followed by model 1 , that was adjusted for physical activity (metabolic equivalent (MET)/week), body mass index (BMI, $\mathrm{kg} / \mathrm{m}^{2}$ ), education level (less than 12 years, between 12 and 14 years, more than 14 years), family history of diabetes (yes/no), hypertension (self-reported or use of blood pressure lowering drugs: yes vs. no), hypercholesterolemia (self-reported blood cholesterol $>6.2 \mathrm{mmol} / \mathrm{l}$ or use of cholesterol lowering drugs: yes vs. no), hyper or hypothyroidism (yes/no), and smoking status (non-smoker, former smoker, smoker). The model was corrected for adherence scores to the healthy dietary pattern and the western dietary pattern, both derived with principal components analysis (PCA), as previously described (26).

We performed a second set of analyses by adding the following variables one at a time to models 1 in order to identify whether they had an impact on the relationship between dietary iodine intake and the risk of type 2 diabetes: retinol, omega 3 fatty acids, phosphorus, zinc, 
135 calcium, sodium, copper, and iron. Variables were retained if they modified the HR for the $5^{\text {th }}$ quintile group for more than \pm 0.05 . Taking into account the results of this second set of analyses, only phosphorus was retained leading to models 2 .

To assess the association between iodine intake and the risk of diabetes independently of the main sources of iodine in our population, model 2 was adjusted for the consumption of the main iodine providers, i.e. dairy products and seafood, leading to the final model (Model 3). Tests for linear trends were performed for all models by assigning the median value to each iodine intake quintile and modeling this value as a continuous variable. To better characterize the shape of the association between iodine intake and T2D risk highlighted by the final model a spline regression was performed.

We tested the interaction between dietary iodine intake, and BMI $\left(<25 \mathrm{~kg} / \mathrm{m}^{2}\right.$ vs. $\geq 25$ $\mathrm{kg} / \mathrm{m}^{2}$ ) and the presence of hyper/hypothyroidism (yes/no), and when the interaction test was statistically significant we performed a test of homogeneity between the groups.

Missing values were $<5 \%$ for all variables and were imputed with the median of the study population (quantitative variables) or the mode (qualitative variables).

\section{Sensitivity analysis}

To test a reverse causality hypothesis, we also assessed the association between dietary iodine intake and the risk of type 2 diabetes, excluding diabetes cases that occurred during the first 5 years of follow-up.

Finally, as the residual method and the nutrient density method (nutrient intake divided by total energy intake) are based on different assumptions concerning the relationship between nutrient intake and total energy intake, and thus potentially provide different results, all analyses were repeated using the nutrient density method. 

using SAS software, version 9.4.

\section{Results}

The average iodine intake in our population was $155.6 \mu \mathrm{g} / \mathrm{day}( \pm 47.1)$. In Table 1 the study

163 population is described according to quintiles of iodine intake. Women with high iodine intakes were younger and had higher BMI than those with low iodine intakes. Increasing iodine intake was associated with increasing percentages of incident type 2 diabetes cases and of hyper/hypothyroidism cases.

The main contributors to iodine intake in our population were dairy products and seafood, with $34.8 \%$ and $14.5 \%$ of the total iodine intake, respectively (Table 2). Water (8.8\%), cereal products $(8.6 \%)$ and eggs $(7.6 \%)$ were the next most important sources of iodine.

On average every women was followed for $13.4( \pm 2.9)$ years, for a total of 958359 person-years. High iodine intakes were associated with a higher risk of developing type 2 diabetes, even after adjusting for the main confounding factors (Table 3). Model 1, which was adjusted for the main risk factors for diabetes and hyper / hypothyroidism, showed an increased risk of type 2 diabetes for iodine intakes in the $4^{\text {th }}$ and $5^{\text {th }}$ quintile groups compared to the $1^{\text {st }}$ quintile group. Indeed the HRs (95\% CI) for quintiles 4 and 5 were $1.25(1.10-1.43)$ and 1.26 (1.11-1.43), respectively.

Phosphorus was the only variable, among those tested, which had an impact on the relationship between iodine intake and the risk of type 2 diabetes modifying the HR for the $5^{\text {th }}$ quintile group for more than \pm 0.05 (Supplemental Table 1). In model 2, i.e. model 1 additionally adjusted for phosphorus intakes, the HRs $(95 \% \mathrm{CI})$ for the $4^{\text {th }}$ and $5^{\text {th }}$ quintile groups were 1.21 (1.06-1.40), and 1.17 (1.01-1.38), respectively (Table 3). 
Finally, model 3, which corresponds to model 2 further adjusted for dairy products and seafood consumption, highlighted an increased risk of type 2 diabetes from the $4^{\text {th }}$ quintile of iodine intake compared to the $1^{\text {st }}$ quintile group. The HRs $(95 \% \mathrm{CI})$ for $4^{\text {th }}$ and $5^{\text {th }}$ quintile groups were respectively $1.27(1.10-1.47)$ and $1.28(1.07-1.53)$ (Table 3).

There was a linear component of trend across quintiles of iodine intake ( $\left.\mathrm{p}_{\text {trend }} 0.006\right)$ starting from the $3^{\text {rd }}$ quartile group, which appears clearly from the graph obtained from spline regression model (Figure 1).

There was no effect modification of the association between iodine intake and risk of type 2 diabetes by BMI or the presence of hyper / hypothyroidism $\left(\mathrm{p}_{\text {interaction }}=0.25\right.$ and $\mathrm{p}=0.32$, respectively).

\section{Sensitivity analysis}

To test the hypothesis of reverse causality between iodine intake and the risk of type 2 diabetes, we excluded the 392 cases of diabetes detected during the first 5 years of follow-up. We also re-analyzed model 4 using the nutrient density method on all micronutrients. The results obtained with these two models were not different from the results of the initial model 4 (data not shown).

\section{Discussion}

In our population, high iodine intake is associated with an increased risk of type 2 diabetes. To our knowledge, this is the first study that investigates the relationship between dietary iodine intake and the risk of developing type 2 diabetes. The relationship appears linear and is associated with a significant increase in risk from the $4^{\text {th }}$ quintile of iodine intake (i.e. above $160.7 \mu \mathrm{g} /$ day). The association was stable across the various tested models, i.e. adjustment for the main potential confounders and sensitivity analyses. 


\section{Biological mechanisms}

Iodine intake has mainly been studied in relation to its capacity of interfering with the thyroid function; nevertheless, the observed association with type 2 diabetes can be supported by two main potential biological mechanisms.

First, we can hypothesize a direct effect of iodine on glucose metabolism and insulin resistance, although biological studies to support this theory are currently missing. Up to date, most studies have focused on the effects of chronic iodine deficiency on the human organism, but very few focused on high dietary intake of iodine, which seems to be the case in our population. The second possible explanation is that the association between iodine intake and type 2 diabetes is actually mediated by the presence of undiagnosed thyroid dysfunction. A previous study estimated that the mean prevalence of undiagnosed hypo- or hyperthyroidism in Europe is $4.94 \%(4.75 \%-5.13 \%)$ and $1.72 \%(1.66 \%-1.88 \%)$, respectively, with a clear female predominance (8.12\% vs 5.19\%), especially regarding hyperthyroidism (27). According to that study, $50 \%$ of cases of hypo- and hyperthyroidism remain undiagnosed. Comparably, the American Association of Clinical Endocrinologists (AACE) estimated that in the United States approximately 13 million people, or $4.78 \%$ of the population, have undiagnosed thyroid dysfunction (28). It is known that excess iodine can lead to thyroid dysfunction and in particular to hyperthyroidism, and that hyperthyroidism is associated with insulin resistance and impaired glucose metabolism $(14,15)$. This may explain the association found in the present study, i.e. an increased risk of developing type 2 diabetes when the mean iodine consumption exceeds $160 \mu \mathrm{g}$ per day.

\section{Strengths and limitations}

Our study presents some limitations. Iodine dietary intakes were estimated through the use of self-administrated questionnaire, thus it is possible that the total amount of iodine could be 
underestimated. Moreover, the dietary estimates are based on a single questionnaire, thus dietary habits changes could not be taken into account leading to possibility for misclassification of exposure. However, as the study is prospective, any effects are likely to be non-differential and would lead to an attenuation of the true association. The fact that our study population includes only women can be considered as a minor limitation due to the fact that few studies have reported differences in T2D risk factors between sexes, although biological mechanisms may differ between men and women.

Finally, the iodine intake in the present work does not take into account iodine-enriched salt. However, this should not have a big impact on the total intake as the added salt (cooking salt and voluntary addition salt), in western countries, accounts for less than $20 \%$ of the total salt intake $(29,30)$ of which, in France, less than $50 \%$ is enriched with iodine (31). Nevertheless, this lack of information on iodine-enriched salt suggests that the iodine intake of the study population is probably underestimated. The true association between dietary iodine intake and type 2 diabetes may therefore be stronger than reported in the present study.

Our study has also several strengths. The response rate remains very high even after 20 years of follow-up, and the questionnaires are carefully completed by the participants (as shown by satisfactory results in validation studies and questionnaire response rates), thus ensuring high reliability. All participants are members of the MGEN, which provides access to comprehensive medical and administrative data. The large size of the study population and the prospective design of the E3N-EPIC cohort allowed us to perform sensitivity analyses while retaining sufficient statistical power to detect associations and make a reverse causation bias unlikely. We analyzed only validated cases of type 2 diabetes, based on a well-defined validation algorithm, which reduces the risk of false negatives or false positives. Finally, detailed information on potential confounders was collected, thus minimizing the risk of residual confounding. 

277 final version.

\section{Conclusion}

Most studies in the literature focus on the health effects of iodine deficiency. Nevertheless, the increased accessibility to seafood due to the improvement in conservation and distance transportation, suggests that iodine deficiency in a developed country such as France is less frequent than in previous periods.In our population, the mean iodine intake is above the recommended nutritional intake despite the fact that the estimated intake is probably underestimated. Our work highlights for the first time a higher risk of type 2 diabetes with high iodine intake. The study should be replicated in other populations with high iodine intake and potentially on other cardiometabolic health outcomes, in order to have a better overview of the health impact of this increasingly consumed nutrient.

Acknowledgments: The authors are grateful to all participants for providing the data used in the E3N-EPIC Study. The Inserm E3N-EPIC cohort, was established and maintained with the support of the MGEN (Mutuelle Générale de l'Education Nationale), the Gustave Roussy Institute, and the French League against Cancer. The validation of potential diabetes cases was supported by the European Union (Integrated Project LSHM-CT-2006-037197 in the 6th European Community Framework Programme) InterAct project. The study is also supported by the French Research Agency (ANR grant, ANR-10-COHO-0006).

Authors' Statement of Contributions: FRM conceived and designed the study. FRM, TH and GF performed the statistical analysis. FRM drafted the original manuscript. All authors contributed to the interpretation of data discussed in the manuscript, revised the manuscript and approved its 


\section{Bibliography}

1. Vought RL and London WT. Iodine intake, excretion and thyroidal accumulation in healthy subjects. J Clin Endocrinol Metab 1967;27:913-919.

2. Nath SK, Moinier B, Thuillier F, Rongier M and Desjeux JF. Urinary excretion of iodide and fluoride from supplemented food grade salt. International Journal for Vitamin and Nutrition Research.1992;62:66-72.

3. World Health Organization. Iodine and health: eliminating iodine deficiency disorders safely through salt iodization. 1994. Available from: http://apps.who.int/iris/bitstream/10665/58693/1/WHO_NUT_94.4.pdf?ua=1

4. EFSA NDA Panel (EFSA Panel on Panel on Dietetic Products Nutrition and Allergies), 2014. Scientific Opinion on Dietary Reference Values for iodine. EFSA Journal 2014;12(5):3660.

5. Laurberg P, Pedersen KM, Hreidarsson A, Sigfusson N, Iversen E and Knudsen PR. Iodine intake and the pattern of thyroid disorders: a comparative epidemiological study of thyroid abnormalities in the elderly in Iceland and in Jutland, Denmark. J Clin EndocrinolMetab 1998;83:765-769.

6. Teng W, Shan Z, Teng X, Guan H, Li Y, Teng D, Jin Y, Yu X, Fan C, Chong W, Yang F, Dai H, Yu Y, Li J, Chen Y, Zhao D, Shi X, Hu F, Mao J, Gu X, Yang R, Tong Y, Wang $\mathrm{W}$, Gao T and Li C. Effect of iodine intake on thyroid diseases in China. N Engl J Med. 2006;354:2783-2793.

7. Wang C. The relationship between type 2 diabetes mellitus and related thyroid diseases. $\mathbf{J}$ Diabetes Res. 2013;2013:390534.

8. Al-Geffari M, Ahmad NA, Al-Sharqawi AH, Youssef AM, Alnaqeb D, Al-Rubeaan K. Risk factors for thyroid dysfunction among type 2 diabetic patients in a highly diabetes mellitus prevalent society. Int J Endocrinol. 2013;2013:417920.

9. Hage M, Zantout MS, Azar ST. Thyroid disorders and diabetes mellitus. J Thyroid Res 2011;2011:439463.

10. Maratou E, Hadjidakis DJ, Kollias A, Tsegka K, Peppa M, Alevizaki M, Mitrou P, Lambadiari V, Boutati E, Nikzas D, Tountas N, Economopoulos T, Raptis SA, Dimitriadis G. Studies of insulin resistance in patients with clinical and subclinical hypothyroidism. Eur. J. Endocrinol. 2009;160:785-790.

11. Brenta G, Celi FS, Pisarev M, Schnitman M, Sinay I, Arias P. Acute thyroid hormone withdrawal in athyreotic patients results in a state of insulin resistance. Thyroid. 2009; 19:665-669.

12. Debiec H, Cross HS, Peterlik M, D-glucose uptake is increased in jejunal brush-border membrane vesicles from hyperthyroid chicks. Acta. Endocrinol. 1989;120:435-441.

13. Cavallo-Perin P, Bruno A, Boine L, Cassader M, Lenti G, Pagano G. Insulin resistance in Graves' disease: a quantitative in vivo evaluation. Eur. J. Clin. Invest. 1988;18:607-613.

14. MaratouE, Hadjidakis DJ, Peppa M, Alevizaki M, Tsegka K, Lambadiari , Mitrou P, Boutati E, Kollias A, Economopoulos T, Raptis SA, Dimitriadis G. Studies of insulin 
resistance in patients with clinical and subclinical hyperthyroidism. Eur. J. Endocrinol. 2010;163:625-630.

15. Bhattacharyya A and Wiles PG, Diabetic ketoacidosis precipitated by thyrotoxicosis. Postgrad. Med. J. 1999;75:291-292.

16. Guastamacchia E, Triggiani V, Aglialoro A, Aiello A, Ianni L, Maccario M, Zini M, Giorda C, Guglielmi R, Betterle C, Attanasio R, Borretta G, Garofalo P, Papini E, Castello R, Ceriello A. Italian Association of Clinical Endocrinologists (AME) \& Italian Association of Clinical Diabetologists (AMD) Position Statement : Diabetes mellitus and thyroid disorders: recommendations for clinical practice.

Endocrine. 2015;49:339-352.

17. World Health Organization. Global report on diabetes. 2016. Available from: http://apps.who.int/iris/bitstream/10665/204871/1/9789241565257_eng.pdf

18. Clavel-Chapelon F; E3N Study Group. Cohort Profile: The French E3N Cohort Study. Int J Epidemiol. 2015;44:801-809.

19. Riboli E, Hunt KJ, Slimani N, Ferrari P, Norat T, Fahey M, et al. European Prospective Investigation into Cancer and Nutrition (EPIC): study populations and data collection. Public Health Nutr. 2002;5:1113-1124.

20. Langenberg C, Sharp SJ, Franks PW, Scott RA, Deloukas P, Forouhi NG, et al. Genelifestyle interaction and type 2 diabetes: the EPIC interact case-cohort study. PLoS Med. 2014;11:e1001647.

21. Van Liere MJ, Lucas F, Clavel F, Slimani N, Villeminot S. Relative validity and reproducibility of a French dietary history questionnaire. Int J Epidemiol. 1997;26 Suppl 1:S128-136.

22. Favier J-C, Ireland-Ripert J, Toque C, Feinberg M. Répertoire général des aliments : table de composition. Paris: Technique \& Documentation; 1995. Available from: http://horizon.documentation.ird.fr/exl-doc/pleins textes/divers11-10/39105.pdf

23. Paul AA, Southgate D a. T. McCance and Widdowson's The Composition of Foods. SpringerLink. 1987;129-131.

24. Willett WC, Howe GR, Kushi LH. Adjustment for total energy intake in epidemiologic studies. Am J Clin Nutr. 1997;65:1220S-1228S.

25. Brown CC, Kipnis V, Freedman LS, Hartman AM, Schatzkin A, Wacholder S. Energy adjustment methods for nutritional epidemiology: the effect of categorization. Am J Epidemiol. 1994 1;139:323-38.

26. Bédard A, Garcia-Aymerich J, Sanchez M, Le Moual N, Clavel-Chapelon F, BoutronRuault MC, Maccario J, Varraso R. Confirmatory Factor Analysis Compared with Principal Component Analysis to Derive Dietary Patterns: A Longitudinal Study in Adult Women. J Nutr. 2015 Jul;145(7):1559-68.

27. Garmendia Madariaga A, Santos Palacios S, Guillén-Grima F, Galofré JC. The incidence and prevalence of thyroid dysfunction in Europe: a meta-analysis. J Clin Endocrinol Metab. 2014;99:923-931. 
28. Garber JR, Cobin RH, Gharib H, Hennessey JV, Klein I, Mechanick JI, Pessah-Pollack R, Singer PA, Woeber KA; American Association of Clinical Endocrinologists and American Thyroid Association Taskforce on Hypothyroidism in Adults. Clinical practice guidelines for hypothyroidism in adults: cosponsored by the American Association of Clinical Endocrinologists and the American Thyroid Association. Endocr Pract. 2012;18:988-1028.

29. Mattes RD1, Donnelly D. Relative contributions of dietary sodium sources. J Am Coll Nutr. 1991;10:383-393.

30. James W.P.T., Ralph A., Sanchez-Castillo C.P. - The dominance of salt in manufactured food in the sodium intake of affluent societies. Lancet. 1987;1:426-429.

31. Comité des Salines de France. - Rapport du Délégué Général, 2003. http://www.salines.com/sel-savoir-faire/alimentation/sels-iodes-fluores/sel-iode/ 
Table 1. Characteristics (\% or mean (SD)) of the study population according to quintile groups of dietary iodine intake (n=71 264). The E3N-EPIC cohort

\begin{tabular}{|c|c|c|c|c|c|}
\hline \multirow[b]{2}{*}{ Variables } & \multicolumn{5}{|c|}{ Quintile groups of dietary iodine intake } \\
\hline & $\begin{array}{c}1 \\
(n=14253)\end{array}$ & $\begin{array}{c}2 \\
(n=14252)\end{array}$ & $\begin{array}{c}3 \\
(n=14254)\end{array}$ & $\begin{array}{c}4 \\
(n=14252)\end{array}$ & $\begin{array}{c}5 \\
(n=14253)\end{array}$ \\
\hline Iodine intake $(\mu \mathrm{g} / \mathrm{day})$ & $98.93(14.21)$ & $128.25(6.33)$ & $149.57(6.25)$ & $174.34(8.51)$ & $227.17(35.59)$ \\
\hline \multicolumn{6}{|c|}{ Non dietary variables } \\
\hline Age (years) & $53.58(6.84)$ & $53.02(6.72)$ & $52.77(6.69)$ & $52.56(6.53)$ & $52.5(6.5)$ \\
\hline BMI $\left(\mathrm{kg} / \mathrm{m}^{2}\right)$ & $22.36(2.95)$ & $22.66(2.97)$ & $22.87(3.07)$ & $23.02(3.20)$ & $23.52(3.53)$ \\
\hline Family history of diabetes (\%) & 10.15 & 11.30 & 10.66 & 11.58 & 11.91 \\
\hline Hypercholesterolemia(\%) & 38.03 & 38.08 & 39.17 & 38.56 & 35.49 \\
\hline Hypertension (\%) & 13.27 & 12.59 & 13.37 & 13.44 & 14.07 \\
\hline Physical activity (METs h/week) & $46.58(52.59)$ & $47.66(51.95)$ & $47.87(43.02)$ & $50.62(49.27)$ & $54.16(54.63)$ \\
\hline \multicolumn{6}{|l|}{ Smoking } \\
\hline Current $(\%)$ & 15.05 & 13.28 & 13.25 & 12 & 13.47 \\
\hline Former $(\%)$ & 30.93 & 32.56 & 33.11 & 33.10 & 33.28 \\
\hline \multicolumn{6}{|l|}{ Education } \\
\hline$<12$ years of $(\%)$ & 14.10 & 12.88 & 13.36 & 13.59 & 15.26 \\
\hline $12-14$ years $(\%)$ & 49.76 & 51.25 & 52.09 & 51.83 & 50.19 \\
\hline$>14$ years $(\%)$ & 36.14 & 35.88 & 34.55 & 34.58 & 34.55 \\
\hline Hyper/ hypothyroidism (\%) & 14.61 & 15.16 & 15.86 & 16.50 & 17.44 \\
\hline Type 2 diabetes incident cases (\%) & 2.88 & 3.12 & 3.69 & 4.18 & 4.82 \\
\hline \multicolumn{6}{|c|}{ Dietary variables } \\
\hline $\begin{array}{l}\text { Energy intake without } \\
\text { carbohydrates and alcohol } \\
\text { (kcal/day) }\end{array}$ & $901.06(200.66)$ & $1066.61(212.15)$ & $1177.26(234.27)$ & $1292.17(259.6)$ & $1516.11(332.18)$ \\
\hline Alcohol intake (g ethanol/day) & $10.83(13.61)$ & $11.03(13.15)$ & $11.49(13.48)$ & $11.89(14)$ & $12.73(14.99)$ \\
\hline Carbohydrates intake (g/day) & $190.88(54.41)$ & $216.86(58.35)$ & $233.52(62.54)$ & $252.02(68.33)$ & $281.71(77.7)$ \\
\hline Vitamin A intake ( $\mu \mathrm{g} /$ day $)$ & $806.58(794.9)$ & $1032.36(929.31)$ & $1197.3(1072.21)$ & $1364.87(1186.45)$ & $1711.11(1519.81)$ \\
\hline
\end{tabular}


Omega 3 intake (g/day)

Phosphorus intake (mg/day)

Zinc intake (mg/day)

Calcium intake (mg/day)

Sodium intake (mg/day)

Copper intake (mg/day)

Iodine intake/total energy intake

Iron intake (mg/day)

\begin{tabular}{c|c|c|c|c}
\hline $1.10(0.33)$ & $1.33(0.36)$ & $1.49(0.40)$ & $1.66(0.45)$ & $2.03(0.61)$ \\
\hline $1064.06(198)$ & $1286.03(189.01)$ & $1443.86(203.95)$ & $1616.57(226.76)$ & $1976(346.11)$ \\
\hline $8.83(2.33)$ & $10.3(2.36)$ & $11.35(2.5)$ & $12.43(2.69)$ & $14.62(3.25)$ \\
\hline $695.07(167.72)$ & $888.09(167.15)$ & $1029.08(189.04)$ & $1188.17(219.02)$ & $1529.38(365.85)$ \\
\hline $2182.04(651.85)$ & $2564.47(698.01)$ & $2808.22(740.85)$ & $3080.28(810.50)$ & $3560.35(962.18)$ \\
\hline $2.38(0.96)$ & $2.66(1.04)$ & $2.87(1.16)$ & $3.06(1.25)$ & $3.52(1.51)$ \\
\hline $0.06(0.01)$ & $0.07(0.01)$ & $0.07(0.02)$ & $0.08(0.02)$ & $0.09(0.02)$ \\
\hline $11.72(2.75)$ & $13.33(2.88)$ & $14.45(3.1)$ & $15.61(3.42)$ & $17.79(4.06)$ \\
\hline
\end{tabular}


Table 2. Percentage contribution of the main food groups to the total dietary iodine intake. The E3N-EPIC cohort

\begin{tabular}{c} 
Food group $\quad \begin{array}{c}\text { Contribution to the total iodine intake } \\
(\%)\end{array}$ \\
\hline
\end{tabular}

Dairy products

34.82

Seafood

14.53

Water

8.78

Cereal products

8.58

Eggs

7.64

Hot beverages (the, café...)

Fruit and vegetables

5.40

Others 
Table 3. Hazard ratios (95\% CI) estimated by Cox multivariable regression models for the risk of incident type 2 diabetes according to quintile groups of dietary iodine intake ( $\mu \mathrm{g} /$ day) estimated by the residual method ( $\mathrm{n}=71264)$. The E3N-EPIC cohort

\begin{tabular}{|c|c|c|c|c|c|c|}
\hline \multicolumn{7}{|c|}{ Quintile groups of dietary iodine intake ( $\mu \mathrm{g} / \mathrm{day})$} \\
\hline & $1^{\text {st }}$ & $2^{\text {nd }}$ & $3^{\text {rd }}$ & $4^{\text {th }}$ & $5^{\text {th }}$ & $P$ trend \\
\hline $\begin{array}{l}\text { Daily } \\
\text { intake }\end{array}$ & 29.3-116.9 & $117.0-138.9$ & $139.0-160.7$ & 160.8-190.6 & $190.7-596.8$ & \\
\hline Model 0 & REF & $\begin{array}{c}1.13 \\
(0.99-1.29)\end{array}$ & $\begin{array}{c}1.20 \\
(1.05-1.36)\end{array}$ & $\begin{array}{c}1.44 \\
(1.27-1.64)\end{array}$ & $\begin{array}{c}1.70 \\
(1.50-1.92)\end{array}$ & $<0.0001$ \\
\hline Model 1 & REF & $\begin{array}{c}1.11 \\
(0.97-1.27)\end{array}$ & $\begin{array}{c}1.11 \\
(0.97-1.27)\end{array}$ & $\begin{array}{c}1.25 \\
(1.10-1.43)\end{array}$ & $\begin{array}{c}1.26 \\
(1.11-1.42)\end{array}$ & $<0.0001$ \\
\hline Model 2 & REF & $\begin{array}{c}1.10 \\
(0.96-1.26)\end{array}$ & $\begin{array}{c}1.09 \\
(0.95-1.25)\end{array}$ & $\begin{array}{c}1.21 \\
(1.06-1.40)\end{array}$ & $\begin{array}{c}1.17 \\
(1.01-1.38)\end{array}$ & 0.0009 \\
\hline Model 3 & REF & $\begin{array}{c}1.12 \\
(0.97-1.28)\end{array}$ & $\begin{array}{c}1.12 \\
(0.97-1.29)\end{array}$ & $\begin{array}{c}1.27 \\
(1.10-1.47)\end{array}$ & $\begin{array}{c}1.28 \\
(1.07-1.53)\end{array}$ & 0.006 \\
\hline
\end{tabular}

Model 0: univariate

Model 1: adjusted for physical activity (MET/week), BMI (kg/m2), education level (less than 12 years, between 12 and 14 years, more than 14 years), hypertension (yes/no), family history of diabetes (yes/no), hypercholesterolemia (yes/no), hyper / hypothyroidism (yes/no), smoking status (non-smoker, former smoker, smoker) adherence to the Western diet (as continuous variable) and adherence to the Mediterranean diet (as continuous variable).

Model 2: Model $1+$ phosphorus intake ( $\mu \mathrm{g} / \mathrm{day})$

Model 3: Model 2 + dairy products and seafood consumption (gr/day) 
Figure 1.Spline regression model between the dietary iodine intake $(\mu \mathrm{g} / \mathrm{day})$ estimated by the residual method and the risk of type 2 diabetes ( $n=71264)$. The E3N-EPIC cohort.

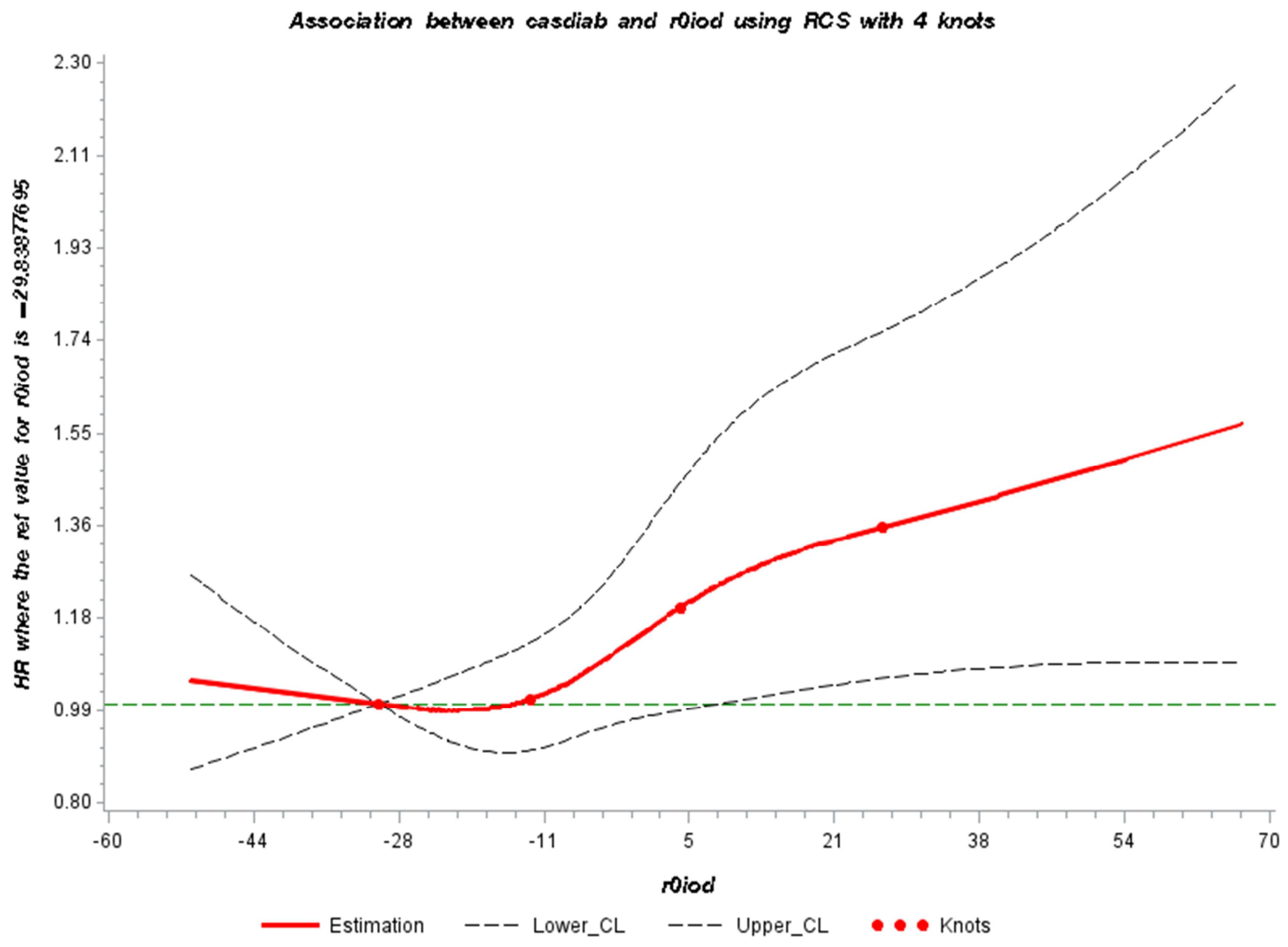

Spline regression (4 knots): the model was adjusted for physical activity (MET/week), BMI $\left(\mathrm{kg} / \mathrm{m}^{2}\right)$, education level (less than 12 years, between 12 and 14 years, more than 14 years), hypertension (yes/no), family history of diabetes (yes/no), hypercholesterolemia (yes/no), hyper / hypothyroidism (yes/no), smoking status (non-smoker, former smoker, smoker) adherence to the Western diet (as continuous variable) and adherence to the Mediterranean diet (as continuous variable), phosphorus intake ( $\mu \mathrm{g} /$ day), dairy products consumption and seafood consumption (gr/day) 
Online supporting material.

Supplemental Table 1: Results of the stepwise approach: hazard ratios (95\%CI) for the risk of incident type 2 diabetes according to quintiles of dietary iodine intake ( $\mu \mathrm{g} /$ day) adding one by one the dietary variables to model 1 and model 2. The E3N-EPIC cohort

\begin{tabular}{|c|c|c|c|c|c|c|}
\hline \multicolumn{7}{|c|}{ Quintile groups of dietary iodine intake ( $\mu \mathrm{g} / \mathrm{day})$} \\
\hline & $1^{\text {st }}$ & $2^{\text {nd }}$ & $3^{\text {rd }}$ & $4^{\text {th }}$ & $5^{\text {th }}$ & $P$ trend \\
\hline Daily intake & 29.3-116.9 & $117.0-138.9$ & $139.0-160.7$ & $160.8-190.6$ & $190.7-596.8$ & \\
\hline $\begin{array}{c}\text { Model 1 + } \\
\text { vitamin A }\end{array}$ & REF & $\begin{array}{c}1.10(0.96- \\
1.26)\end{array}$ & $\begin{array}{c}1.10(0.96- \\
1.26)\end{array}$ & $\begin{array}{c}1.24(1.09- \\
1.41)\end{array}$ & $\begin{array}{c}1.22(1.07- \\
1.40)\end{array}$ & 0.002 \\
\hline $\begin{array}{l}\text { Model } 1+ \\
\text { omega } 3\end{array}$ & REF & $\begin{array}{c}1.10(0.96- \\
1.26)\end{array}$ & $\begin{array}{c}1.11(0.97- \\
1.26)\end{array}$ & $\begin{array}{l}1.24(1.11- \\
1.42)\end{array}$ & $\begin{array}{l}1.23(1.11- \\
1.41)\end{array}$ & 0.002 \\
\hline$\frac{\text { Model 1+ }}{\text { phosphorus }}$ & REF & $\begin{array}{c}1.10(0.96- \\
1.26)\end{array}$ & $\begin{array}{c}1.11(9.95- \\
1.25)\end{array}$ & $\begin{array}{l}1.21(1.06- \\
1.40)\end{array}$ & $\begin{array}{c}1.18(1.00- \\
1.38)\end{array}$ & 0.050 \\
\hline $\begin{array}{l}\text { Model } 1+ \\
\text { zinc }\end{array}$ & REF & $\begin{array}{c}1.10(0.96- \\
1.26)\end{array}$ & $\begin{array}{c}1.10(0.96- \\
1.26)\end{array}$ & $\begin{array}{l}1.23(1.08- \\
1.40)\end{array}$ & $\begin{array}{l}1.20(1.05- \\
1.40)\end{array}$ & 0.005 \\
\hline $\begin{array}{l}\text { Model } 1+ \\
\text { calcium }\end{array}$ & REF & $\begin{array}{c}1.12(0.97- \\
1.28)\end{array}$ & $\begin{array}{c}1.12(0.98- \\
1.29)\end{array}$ & $\begin{array}{c}1.27(1.11- \\
1.47)\end{array}$ & $\begin{array}{c}1.28(1.09- \\
1.51)\end{array}$ & 0.003 \\
\hline $\begin{array}{l}\text { Model } 1+ \\
\text { sodium }\end{array}$ & REF & $\begin{array}{c}1.10(0.97- \\
1.27)\end{array}$ & $\begin{array}{c}1.11(0.97- \\
1.27)\end{array}$ & $\begin{array}{l}1.25(1.10- \\
1.42)\end{array}$ & $\begin{array}{c}1.23(1.08- \\
1.41)\end{array}$ & 0.001 \\
\hline $\begin{array}{l}\text { Model } 1+ \\
\text { copper }\end{array}$ & REF & $\begin{array}{c}1.11(0.97- \\
1.27)\end{array}$ & $\begin{array}{c}1.11(0.97- \\
1.27)\end{array}$ & $\begin{array}{c}1.25(1.10- \\
1.43)\end{array}$ & $\begin{array}{l}1.24(1.09- \\
1.42)\end{array}$ & 0.001 \\
\hline $\begin{array}{l}\text { Model 1 + } \\
\text { iron }\end{array}$ & REF & $\begin{array}{c}1.11(0.97- \\
1.27)\end{array}$ & $\begin{array}{c}1.11(0.97- \\
1.27)\end{array}$ & $\begin{array}{c}1.25(1.10- \\
1.43)\end{array}$ & $\begin{array}{c}1.24(1.08- \\
1.42)\end{array}$ & 0.001 \\
\hline
\end{tabular}

